\title{
Local adaptations and phenotypic plasticity may render gypsy moth and nun moth future pests in northern European boreal forests.
}

\begin{tabular}{|c|c|}
\hline Journal: & Canadian Journal of Forest Research \\
\hline Manuscript ID & cjfr-2016-0481.R1 \\
\hline Manuscript Type: & Article \\
\hline Date Submitted by the Author: & 24-Feb-2017 \\
\hline Complete List of Authors: & $\begin{array}{l}\text { Fält-Nardmann, Julia; University of Turku, Department of Biology; } \\
\text { Technische Universitat Dresden, Professur für Forstzoologie } \\
\text { Klemola, Tero; University of Turku, Department of Biology; University of } \\
\text { Turku, Kevo Subarctic Research Institute } \\
\text { Ruohomäki, Kai; University of Turku, Department of Biology } \\
\text { Niemelä, Pekka; University of Turku, Department of Biology } \\
\text { Roth, Mechthild; Technische Universitat Dresden, Professur für } \\
\text { Forstzoologie } \\
\text { Saikkonen, Kari; Natural Resources Institute Finland, }\end{array}$ \\
\hline Keyword: & $\begin{array}{l}\text { Climate change, Local adaptation, }<\mathrm{i}>\text { Lymantria monacha }</ \mathrm{i}>\text {, } \\
<\mathrm{i}>\text { Lymantria dispar }</ \mathrm{i}>\text {, Phenotypic plasticity }\end{array}$ \\
\hline $\begin{array}{l}\text { Please Select from this Special } \\
\text { Issues list if applicable: }\end{array}$ & IUFRO 2016 Special Issue \\
\hline
\end{tabular}


1 Local adaptations and phenotypic plasticity may render gypsy moth and nun moth future pests in

2 northern European boreal forests.

3 Julia J. J. Fält-Nardmann (corresponding author)

4
Department of Biology, University of Turku, FI-20014 Turku, Finland and Professur für Forstzoologie, Technische Universität Dresden, Pienner Straße 7, D-01737 Tharandt, Germany. E-mail: julia.falt@,utu.fi Telephone: +49(0) 352033831366

Tero Klemola

Department of Biology, University of Turku, FI-20014 Turku, Finland.

and Kevo Subarctic Research Institute, University of Turku, FI-20014 Turku, Finland. E-mail: tero.klemola@utu.fi

Kai Ruohomäki

Department of Biology, University of Turku, FI-20014 Turku, Finland.

and Kevo Subarctic Research Institute, University of Turku, FI-20014 Turku, Finland. E-mail: kai.ruohomaki@utu.fi

Pekka Niemelä

Department of Biology, University of Turku, FI-20014 Turku, Finland.

E-mail: pekka.niemela@utu.fi

Mechthild Roth

Professur für Forstzoologie, Technische Universität Dresden, Pienner Straße 7, D-01737

Tharandt, Germany. E-mail: mroth@forst.tu-dresden.de

Kari Saikkonen 


\section{Abstract}

Phenotypic plasticity and local adaptations are important factors in predicting range expansions and shifts of pest insects in a changing climate. We reared two lepidopteran forest pests, Lymantria monacha and L. dispar, at three climatically different field sites from central Germany to northern Finland to investigate differences among populations in plasticity in the timing of pupation and adult emergence (measured as cumulative temperature sums, degree days $>5^{\circ} \mathrm{C}$ ), pupal mass, and duration of the pupal period. We also compared the phenologies of continental and boreal L. monacha populations feeding on Scots pine (Pinus sylvestris) to reveal possible local adaptations. Lymantria dispar was reared on different host plants - Quercus robur, Betula pendula and B. pubescens ssp. czerepanovii - to evaluate the possibilities of a range expansion northwards. There was stronger indication of adaptive phenotypic plasticity, which enables species to cope with changing environmental conditions, in continental $L$. dispar and boreal L. monacha populations than in the continental L. monacha population. Differences between boreal and continental L. monacha populations may denote adaptation to local conditions. All three host plants used for L. dispar proved suitable for the species, revealing that host plant availability would not limit its range expansion in Northern Europe.

\section{Keywords: Climate change, Local adaptation, Lymantria monacha, Lymantria dispar, Phenotypic} plasticity 
42

43

44

\section{Introduction}

The influence of climate change on butterflies and moths - especially charismatic, conspicuous species and those considered as forest or agricultural pests - has been investigated intensively in recent years (e.g., Björkman \& Niemelä 2015). The effect of rising temperatures on the distribution ranges of Lepidoptera has been considered (e.g.,Parmesan et al. 1999, Vanhanen et al. 2007, Jepsen et al. 2008, Ammunét et al. 2012, Yasukevich et al. 2015), as well as the possibility for phenological mismatches in synchrony between trophic levels, such as defoliator larvae or pollinators and their host plants (e.g., Buse \& Good 1996, van Asch \& Visser 2007, Memmott et al. 2007, Jepsen et al. 2011, Visser \& Holleman 2001, Foster et al. 2013, Hindle et al. 2015). Several authors have voiced the need to take phenotypic plasticity as well as local adaptations (and even local adaptations of phenotypic plasticity) into account in such studies, as geographically distant populations of the same species may have developed the ability to thrive in different conditions and even to cope with a continuously changing climate (Ammunét et al. 2011, Valtonen et al. 2011, Kaitaniemi et al. 2012, Valladares et al. 2014).

Presumably insects optimize their life cycle in relation to prevailing conditions to obtain maximum fitness. This is facilitated by adaptive phenotypic plasticity of the life stage duration and timing, such as egg hatching, diapausing, pupation, adult emergence and oviposition - in other words by the ability to flexibly adapt the phenology to prevailing environmental conditions (Nylin \& Gotthard 1998, Valtonen et al. 2011, Saikkonen et al. 2012, Valladares et al. 2014). In the life cycle of a univoltine insect, phenological events are commonly dependent on the accumulated temperature sum. Global climate change may influence the rate of temperature accumulation and the average dates when a required temperature sum is reached. However, day length - a variable not influenced by climate change - also commonly controls the timing of insect life cycles either independently or as a modifier of temperature effects (Danks 1987, Tauber et al. 1990, van Asch \& Visser 2007, Valtonen et al. 2011). With sufficient adaptive phenotypic plasticity allowing insects to follow these environmental cues, many species may rapidly become established in new environments, or continue thriving in the changing climate of their 
67

68

current distribution range, without a risk of asynchrony with their host plants before any genetic adaptation takes place.

In this paper we report the results of a field study where we investigated plasticity in the timing of pupation and adult emergence (measured in relation to accumulating temperature sums), pupal mass and the duration of the pupal period in different populations of two forest pests, the nun moth (Lymantria monacha (Linnaeus)) and the gypsy moth (L. dispar (Linnaeus) (Lepidoptera: Erebidae, Lymantriinae)). We examined the phenological differences between the L. monacha populations from continental midGermany and boreal Southern Finland when individuals from these both populations were reared in the same conditions, as these differences may indicate recent local adaptations in the Finnish population. We also investigated, whether L. monacha or L. dispar individuals, originating from the same population, differ in development timing when mesh bag-reared in climatically different field locations

- both in areas where the species occur naturally, and more northern ones where they are not present. A further aim was to examine the timing of life cycle events of $L$. dispar to assess whether it could expand its range northwards in Northern Europe to areas where it is not yet present but where L. monacha is currently spreading (Leinonen et al. 2016). Finally, we wanted to compare L. dispar development on different host plants, namely oak (Quercus robur L.), silver birch (Betula pendula Roth.) and mountain birch (B. pubescens ssp. czerepanovii (Orl.) Hämet-Ahti) under field conditions.

\section{Materials \& Methods}

\subsection{Study species}

Lymantria monacha and L. dispar are both univoltine medium-sized nocturnal moths that overwinter as small, fully developed larvae diapausing in eggs (Leonard 1974, Bejer 1988, Majunke et al. 2004). Both are considered serious forest defoliators and exhibit frequent though irregular outbreaks in at least some parts of their respective distribution ranges. Lymantria monacha occurs in most parts of temperate Europe and Asia (Vanhanen et al. 2007) and prefers conifers, namely Norway spruce (Picea abies (L.) H. Karst.) and Scots pine (Pinus sylvestris L.) as its host plants, although it can also successfully feed 
and develop on a wide range of other conifer and broadleaf species (Keena 2003). The distribution range of $L$. dispar is slightly more southern than that of $L$. monacha. It comprises most of Europe (except for central and northern Fennoscandia and the British Isles) and Asia as well as parts of North America where it was introduced in the mid- $19^{\text {th }}$ century and where it quickly became a major pest species (Forbush \& Fernald 1896, Liebhold et al. 1992, Liebhold et al. 2000). Lymantria dispar is a highly polyphagous generalist feeding on a large range of different tree genera, with Quercus, Betula, Fagus, Larix and Populus species being among the preferred hosts (Lechowicz \& Mauffette 1986).

Previous studies on environmental variables controlling the life cycle of $L$. monacha are scarce. In $L$. dispar egg diapause and hatching are controlled chiefly by temperature, the effect of which may slightly be inhibited by a short day length (Tauber et al. 1990, Gray et al. 1991, Keena 1996, Gray 2010, Wei et al. 2014). An increase in temperature has also been shown to decrease the time needed for larval development for both species. At least in the range between $15{ }^{\circ} \mathrm{C}$ and $25^{\circ} \mathrm{C}$ higher temperatures also increase survival rates for L. dispar but the effect is the opposite for L. monacha (Karolewski et al. 2007). Bogach et al. (1966) and Kireeva (1969) showed that the duration of the pupal phase of L. dispar is influenced by both light and temperature, with longer days and higher temperatures advancing the pupal development.

\subsection{Locations}

The study was conducted at three different sites in central and northern Europe with approximately ten latitudinal degrees between the two subsequent sites (Table 1, Fig. 1). The southernmost (henceforth referred to as "Tharandt") site was located in Tharandter Wald in Saxony, Germany, where both $L$. monacha and L. dispar occur naturally. Here, as in all other locations, L. monacha larvae were reared only on P. sylvestris, while L. dispar was reared on both $Q$. robur and B. pendula. The second site (“Turku”) was located in Southern Finland, Turku, where L. monacha has become more common during the recent decades (Leinonen et al. 2016), but where L. dispar is not present. Here all the L. dispar and some of the L. monacha larvae were reared at the Ruissalo botanical garden, while the remaining $L$. 
117

monacha larvae were reared on naturally regenerated Scots pines near the campus of the University of Turku, $6.5 \mathrm{~km}$ apart, due to the shortage of P. sylvestris in the botanical garden. In Turku L. dispar was reared on Q. robur only. The northernmost site ("Kevo") located at the Kevo Subarctic Research Station in Utsjoki, close to the northern border of Finland, is well beyond the natural range of both Lymantria species. Here $L$. dispar larvae were reared on B. pubescens ssp. czerepanovii, the most abundant broadleaved tree found there, as B. pendula does not grow this far north.

\subsection{Field experiment}

Lymantria monacha eggs were obtained from females reared in mesh bags under field conditions in Tharandter Wald, Germany during the summer 2013, and they represent a second generation bred in captivity. The original females were collected in Brandenburg, Germany (later referred to as the "continental" population, following the definition of biogeographic regions in Europe by the European Environment Agency (2012)) and in the archipelago of South-Western Finland (later referred to as the “boreal” population) in summer 2012. Lymantria dispar eggs were collected from tree trunks in Brandenburg in August 2013. All the eggs were stored in closed glass vials in a climate chamber (Binder KBF 720) in Tharandt. The temperature was gradually lowered being $19.6^{\circ} \mathrm{C}$ on $28^{\text {th }}$ of July when the first $L$. monacha eggs were laid, $15.9^{\circ} \mathrm{C}$ as the newly collected $L$. dispar eggs were added on $21^{\text {st }}$ of August and reaching $0{ }^{\circ} \mathrm{C}$ on $25^{\text {th }}$ of November. On $17^{\text {th }}$ of December, all the eggs were moved into a freezer at the temperature of $-5{ }^{\circ} \mathrm{C}$.

On $3^{\text {rd }}$ of April 2014, the eggs were randomly assigned to experimental groups, although clearly unfertilized red or flat eggs were omitted. Seven broods of continental L. dispar and L. monacha eggs as well as five broods of boreal L. monacha eggs were divided into batches of 16 eggs, with all the eggs in a batch coming from the same brood. Table 1 shows the batches assigned to the three different field sites. All the egg batches were further divided into two glass vials with eight eggs in each to prevent crowding in later phases of the experiment. 
141 All the eggs for the field site in Tharandt were transferred to an open shed on $3^{\text {rd }}$ of April and to the

142 forest on $7^{\text {th }}$ of April, at all times together with a temperature logger. The eggs for Turku were stored at -

$1435{ }^{\circ} \mathrm{C}$ until transported from Tharandt to Turku together with a temperature logger by express mail on 6-

$1447^{\text {th }}$ of May. For the following days, the eggs were kept at room temperature during the nights and

145 outdoors during the days until transferred to the field sites at the Botanical Garden and at the campus on

$14610-17^{\text {th }}$ of May. The eggs for Kevo were stored at $-5^{\circ} \mathrm{C}$ in Tharandt until they were sent by express

147 mail to Turku on $13-14^{\text {th }}$ of May. They were subsequently transported in a cool box by car to Kevo and

148 there stored in a fridge at $+2.6{ }^{\circ} \mathrm{C}$ until $28^{\text {th }}$ of May when the experiment was started.

149 On the study trees the eggs - and later the larvae - were kept in $40 \times 100 \mathrm{~cm}$ mesh bags of fine voile,

150 each of which enclosed a branch on which the larvae could move and feed freely. The 16 eggs of each

151 batch were kept in two bags on the same tree, except for a few cases where no trees large enough to

152 support two bags were available. In these cases, two trees close to each other were used to host one of

153 the two bags of a batch each.

154 At all three sites the experiment was started close to the time of oak or birch budburst to ensure that the

155 neonate $L$. dispar larvae could start feeding directly after hatching. In Tharandt and Turku some of the

156 pines had male cones during the experiment, producing pollen which is a preferred - though not

157 obligatory (personal observation) - food source for L. monacha larvae. Temperature data for the field

158 sites was obtained from nearby weather stations (Tharandt: "Wildacker Tharandter Wald", Turku:

159 "Artukainen", Kevo: "Kevo") and complemented with data logger measurements. Data on day length

160 was obtained using an online calculator (Gerding 2016).

161 The mesh bags were first checked weekly for damages and defoliation. If the branch in the bag was

162 almost completely defoliated (which occasionally happened in the late instars), the larvae were moved

163 to a new bag on another branch.

164 When the first larvae reached the last instar, the bags were checked at two- or three-day intervals for

165 pupae. When the exact date of pupation was not evident, an approximation was used - if the control 
166

167

168

169

170

171

172

173

174

175

176

177

178

179

180

181

182

183

184

185

186

187

interval had been three days, the date in the middle was recorded as the pupating date; if the interval had been two days, every second pupa found that day was recorded for the first day in the interval and every second for the second day in the interval. The pupae were placed individually in plastic cups on a wad of moist Sphagnum moss and the cups were covered with a loose lid (except for Tharandt where they were covered with voile net) and stored in an open shed, out of direct sunlight.

The pupae were sexed and weighed with a precision scale 6-10 days after pupation. Each pupa was weighed three times consecutively on the same day and the average of the three measurements was recorded as the pupal mass. In capital breeders, i.e. moth species that do not feed as adults, the pupal mass of females correlates with the number of eggs they are able to produce (Hough \& Pimentel 1978, Gilbert 1984, Honěk 1993, Tammaru \& Haukioja 1996).

A set of five L. monacha and five L. dispar pupae from a parallel laboratory breeding were weighed once per day from the $5^{\text {th }}$ to the $14^{\text {th }}$ day of their pupal period to assess whether the pupal mass changes as the pupae mature. No considerable changes in pupal mass occurred between the $6^{\text {th }}$ and the $10^{\text {th }}$ day of the pupal period, thus we consider all the pupal masses measured in the experiment to be reliably comparable with each other.

The plastic cups were checked with one- to three-day intervals for emerged adults. The date of emergence was calculated in the same way as the date of pupation. The duration of the pupal period was measured in days.

We used degree days above $5{ }^{\circ} \mathrm{C}(\mathrm{dd} 5)$, i.e. the cumulative sum of daily average temperatures exceeding the base level of $5{ }^{\circ} \mathrm{C}$, as a measurement for timing of the pupation and adult emergence. The temperature sum was used instead of days, as temperature is much more likely to affect insect lifecycle than the simple passing of arbitrary time units. The 5 degrees Celsius threshold was chosen not because of its likely biological relevance for the phenological processes of the study species, but because it is well suited for comparing the progress of spring and summer on the three study sites (Figs. 1, A1). The true developmental threshold temperatures for the different life stages of these L. monacha and L. dispar 
191

192

193

194

195

196

197

198

199

200

201

202

203

204

205

206

207

208

209

210

211

212

213

214

populations are not known, and using a temperature threshold that differs from the one recognized by the moth may lead to false interpretations of differences between moths originating from the same population but reared in different locations. To avoid this problem, we compared the results obtained using the $5{ }^{\circ} \mathrm{C}$ threshold with the results from the same statistical analyses performed using $2-10{ }^{\circ} \mathrm{C}$ with one degree Celsius intervals as threshold values. The $5{ }^{\circ} \mathrm{C}$ threshold for the analyses of pupation and emergence timing gave, most of the time, similar results as higher (up to $10{ }^{\circ} \mathrm{C}$ ) thresholds and was rather conservative in comparison to lower (down to $2{ }^{\circ} \mathrm{C}$ ) thresholds, which tended to reveal more significant differences between the test groups reared at the different sites. Thus, if the true developmental thresholds for L. monacha and L. dispar are higher than $5^{\circ} \mathrm{C}$, the results remain valid, and if they are lower than that, the evidence for the differences we found would be even stronger. The cases where the results obtained using temperature thresholds other than $5{ }^{\circ} \mathrm{C}$ strongly conflict with the ones obtained using $5^{\circ} \mathrm{C}$ are pointed out in the results.

\subsection{Statistical analysis}

Because the experimental design (e.g., numbers of host plants and populations of different origin) differed between Lymantria monacha and L. dispar, they were analysed separately. Nevertheless, the final data available for the analyses did not satisfy full factorial design for either species (see below and

Table 1), obscuring tests of interactions among explanatory factors like the host plant, field site, sex, and population of origin. To obtain the highest possible number of treatment combinations per species, we were forced to merge field site, sex and, in the case of L. monacha also the population of origin, into one fixed factor, henceforth referred to as the test group. This yielded, for example, "continental females reared at Kevo" and "boreal males reared in Tharandt" as two separate groups for the analysis.

Henceforth we refer to differences between test groups of individuals originating from the same population but reared in different locations (such as boreal males reared in Tharandt and boreal males reared in Turku) as intrapopulation differences. Correspondingly, differences between test groups of 
215 individuals of different origins but reared in the same location (such as continental females reared at

216 Kevo and boreal females reared at Kevo) are here called interpopulation differences.

217 We used linear mixed models with the test group as the fixed factor to explain the following response

218 variables: temperature sum at date of pupation, temperature sum at date of adult emergence, pupal mass

219 and duration of pupal period. A priori contrasts were used to determine significant pairwise differences

220 between the test groups of interest. To control for possible effects of genetic differences between the

221 eggs of different females, batch was set as a random explanatory factor in all the models. Similarly,

222 mesh bag (nested within batch) was set as a random factor to account for possible differences (e.g. in

223 shade) between the two bags that each batch was divided into. The significances of the variation that the

224 random explanatory factors accounted for were tested using likelihood-ratio tests (LRTs). A significant

225 difference here means that part of the observed variation in the results can be explained by differences

226 between broods or between the two mesh bags the eggs of a brood were divided into. Investigation of

227 these random effects were not among the aims of this study, but they were accounted for in order to

228 achieve more powerful tests for the fixed factors that were the main target of the study.

229 We refrained from comparing L. dispar groups in Turku, where L. dispar was reared on oak, and Kevo,

230 where L. dispar was reared on birch, as the possible differences may have been contributed by the

231 different host plants. However, we compared L. dispar groups in Tharandt and Kevo reared on the local

232 birch species, B. pendula and B. pubescens ssp. czerepanovii respectively, despite possible differences

233 between these two host species. Betula pubescens ssp. czerepanovii is a potential and the most abundant

234 food source for L. dispar in northern Fennoscandia beyond the distribution range of B. pendula and was,

235 for the purpose of this study, considered similar enough to B. pendula for a comparison to be

236 meaningful.

237 To test the effects of host plants on the timing of phenological events and pupal mass of $L$. dispar in

238 Tharandt, a second set of models was used with the same random explanatory variables and host plant,

239 sex and the interaction between the two as fixed factors. 
240

241

242

243

244

245

246

247

248

249

250

251

252

253

254

255

256

257

258

259

260

261

262

263

264

Model assumptions on the normality and homoscedasticity were checked from residuals. Denominator

degrees of freedom and standard errors of the fixed factors were approximated by the Kenward-Roger adjustment, facilitating accurate F-tests of the fixed factors (Kenward \& Roger 1997, Littell et al. 2006).

The GLIMMIX procedure in SAS v. 9.4 (SAS Institute Inc., Cary) was used for all analyses (Littell et al. 2006, Stroup 2013).

In certain cases, single measurements or moth individuals were omitted from the dataset. This was done in a) 32 cases where the sex of the pupa could not be determined, b) 15 cases where the adult moth at Kevo did not emerge from the pupae during the experimental period outdoors, but over a month later at room temperature (pupal mass and pupation date was still included in the data), c) 10 cases where the pupa was parasitized, d) 4 cases where either the emergence or pupation dates were uncertain (pupal mass was still included in the data) and e) 3 cases where the pupa was clearly dead on the day of weighing (date of pupation was still included in the data, but not pupal mass). In addition, continental $L$. monacha pupae from Kevo were omitted from the analyses, as there were only four of them, one male and three of undetermined sex.

\section{Results}

The number of pupae and emerged adult moths and their share of the original number of eggs in the experiment is presented in Table 1. Figure A1 in the appendix shows the development of summer temperatures and day length as well as the pupation and emergence periods of L. monacha and L. dispar at each field site.

\subsection{Pupation}

Boreal L. monacha larvae pupated at lower temperature sums than continental ones in both Turku and Tharandt (Fig. 2a, b, Table A1). There were intrapopulation differences in the timing of pupation for boreal L. monacha. Both males and females pupated at a lower temperature sum at Kevo than in Tharandt. In addition the males pupated at a lower temperature sum in Turku than in Tharandt, and the females at a lower temperature sum at Kevo than in Turku. No such indications of phenotypic plasticity 
265

266

267

268

269

270

271

272

273

274

275

276

277

278

279

280

281

282

283

284

285

were found in pupation timing between continental L. monacha in Tharandt and Turku (Fig. 2a, b, Table A1). The test group (field site, sex and, in the case of L. monacha also the population of origin were merged into one variable) was a significant fixed factor in the temperature sum model for both species (L. monacha: $F_{9,111.8}=8.2 ; p<0.0001, L$. dispar: $\left.F_{7,202.9}=42.0 ; \mathrm{p}<0.0001\right)$. The batch, as a random factor, was not statistically significant for either species (LRTs: L. monacha: $p=0.13$, L. dispar: $p=0.074$ ), while the mesh bag (nested within the batch) was a significant random factor for both species (LRTs: $L$. monacha: $p=0.0037$, L. dispar: $p=0.0036)$.

Both male and female L. dispar pupated at lower temperature sums at Kevo than in Tharandt. In addition, L. dispar females pupated at a lower temperature sum in Turku than in Tharandt, and the tendency was the same for males (Fig. 2c, Table A1), although for males the significance of the difference varied greatly depending on the temperature threshold used, and could therefore not be reliably determined.

In Tharandt $L$. dispar reared on oak pupated at a lower temperature sum than those reared on birch, the difference in estimates of pupation timing being 55.0 dd5 $(S E=11.0)$. Sex and host plant were both significant fixed factors in the host plant model for $L$. dispar (sex: $F_{1,101.3}=4.08, p=0.046$; host plant: $F_{1}$,

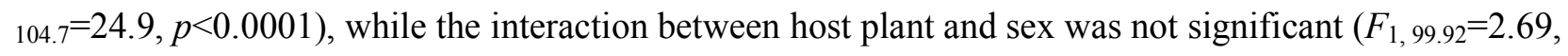
$p=0.104)$.

\subsection{Pupal mass}

Continental Lymantria monacha females were larger than boreal females both in Tharandt and in Turku. There were no significant intrapopulation differences in pupal mass between L. monacha individuals reared at different field sites (Fig. 3a, b, Table A1). The test group (see 3.1 for definition) was a significant fixed factor in the pupal mass model for both species (L. monacha: $F_{9,96.9}=24.3 ; p<0.0001, L$. dispar: $\left.F_{7,199.2}=59.0 ; p<0.0001\right)$. Neither batch nor mesh bag (nested within batch) as a random factor was statistically significant for either species (LRTs: L. monacha: batch: $p=0.45$, mesh bag: $p=0.49 ; L$. dispar: batch: $p=0.19$, mesh bag: $p=0.38)$. 
290

291

292

293

294

295

296

297

298

299

300

301

302

303

304

305

306

307

308

309

310

311

312

313

314

At Kevo the female L. dispar pupae were significantly heavier than in Tharandt (Fig. 3c, Table A1). In

Tharandt pupae were about $0.11 \mathrm{~g}(S E=0.046)$, that is, about $10 \%$, heavier on oak than on birch. Sex and host plant were both significant fixed factors in the host plant model for $L$. dispar (sex: $F_{1}$, $110.9=199.2, p<0.0001$; host plant: $F_{1,111.2}=5.9, p=0.017$ ), while the interaction between host plant and sex was not significant $\left(F_{1,108.3}=0.11, p=0.75\right)$.

3.3 Duration of the pupal period

The only interpopulation difference was the shorter pupal period of continental L. monacha males than that of boreal ones in Turku. Intrapopulation differences among the field sites were found for continental L. monacha males and boreal L. monacha females, both of which had a significantly longer pupal period in Tharandt than in Turku (Fig. 4a,b, Table A1). The test group (see 3.1 for definition) was a significant fixed factor in the model for the duration of the pupal period for both species (L. monacha: $F_{7,53.4}=8.7$; $p<0.0001, L$. dispar: $F_{5,107.8}=7.6 ; p<0.0001$ ). Neither batch, nor mesh bag (nested within the batch) as a random factor was statistically significant for $L$. dispar (LRTs: batch: $p=0.42$, mesh bag: $p=0.42$ ), but mesh bag was significant for L. monacha (LRTs: batch: $p=0.36$, mesh bag: $p=0.014$ ).

Lymantria dispar had a longer pupal period in Tharandt than in Turku (Fig. 4c, d, Table A1). Neither host plant, nor sex or the interaction between the two were significant fixed factors in the host plant model for $L$. dispar (sex: $F_{1,73.6}=2.54, p=0.12$; host plant: $F_{1,73.3}=1.28, p=0.26$; interaction: $F_{1,73.0}=0.28$, $p=0.60)$.

\subsection{Adult emergence}

Continental L. monacha emerged at higher temperature sums than boreal ones (Fig. 5a, b, Table A1). Intrapopulation differences were significant only for boreal male L. monacha, which emerged at a higher temperature sum in Tharandt than in Turku (Fig. 5b, Table A1). The test group (see 3.1 for definition) was a significant fixed factor in the temperature sum model of the timing of adult emergence for both species (L. monacha: $F_{7,73.0}=5.4 ; p<0.0001$, L. dispar: $\left.F_{5,107.7}=7.2 ; p<0.0001\right)$. Neither batch, nor mesh bag (nested within batch) as a random factor was statistically significant for L. dispar (LRTs: 
315 batch: $p=0.14$, mesh bag: $p=0.38$ ), but both were significant for L. monacha (batch LRT: $p=0.021$, mesh 316 bag LRT: $p=0.033)$.

317 Lymantria dispar adults had the tendency to emerge at a lower temperature sum in Turku than in

318 Tharandt, but the significance of the differences in varied greatly depending on what temperature 319 threshold was used, and thus nothing certain can be concluded about them (Fig. 5c, d, Table A1). In 320 Tharandt, L. dispar reared on oak emerged at a lower temperature sum than those reared on birch, the 321 difference in timing being 75.4 dd5 (SE 16.9) which corresponds to 5-6 days (Fig. A1a, Table A1). The 322 host plant was a significant fixed factor in the host plant model for $L$. $\operatorname{dispar}\left(F_{1,69.5}=19.9 ; p<0.0001\right)$, 323 while the sex had no effect on the timing of adult emergence (sex: $F_{1,69.8}=0.07, p=0.79$; host plant $\times$ sex 324 interaction: $\left.F_{1,68.8}=0.09, p=0.77\right)$.

\section{Discussion}

Individuals from all lymantriin populations in the experiment succeeded in pupating and emerging as adults both in Tharandt, Germany and in Turku, Southern Finland. The number of pupae and adults was slightly higher in Tharandt for L. monacha and in Turku for L. dispar (Table 1). All L. monacha and L. dispar failed to complete their entire life cycle at Kevo in the short, cool summer of northern Finland (Fig. A1c). However, a few of the pupae of both species hatched considerably later in mid-October when transferred to room temperature. This suggests that adult emergence in these species is regulated by temperature - either the pupal development slowed down considerably in the low outdoor temperatures and the process was not yet finished by the time the experiment was cancelled, or some threshold temperature or temperature sum crucial for the development was not reached. Although we cannot draw any conclusions about the adaptive nature of this delay based on our data, it is conceivable that such a temperature dependent delay in pupal development would allow the pupae to "wait out" temporary unfavourable cold periods in late summer, postponing adult emergence to a time more favourable for flight. 
339

340

341

342

343

344

345

346

347

348

349

350

351

352

353

354

355

356

357

358

359

360

361

362

363

364

Our temperature sum model revealed interpopulation differences - that is, differences between test moths originating from different populations but reared in the same location - for L. monacha with the boreal ones both pupating and emerging at a lower temperature sum, that is, earlier in the season, than the continental ones (Figs. A1a, b; 2a, b; 5a, b). This may reflect a local adaptation to shorter summers in the boreal L. monacha population. If so, the adaptation may have developed rapidly, as the species was probably established in the country first after the 1950's (Grönblom \& Suomalainen 1950).

However, it would be interesting to compare the Finnish boreal population with its closest neighbours in Sweden and Estonia. Jankovic et al. (1960) discovered similar local differences in timing of life cycle events between northern and southern $L$. dispar populations in former Yugoslavia, and different strains of the species have also been studied at least by Leonard (1966), but to our knowledge no such comparisons have previously been made with L. monacha .

Intrapopulation differences - here referring to differences between moths originating from the same population but reared in different locations - in life cycle timing potentially indicate adaptive phenotypic plasticity that allows fast, within-generation reactions to varying environments. Such differences between locations were most evidently absent for continental L. monacha. They pupated and emerged at approximately the same temperature sum both in Turku and in Tharandt (Figs. 2a, b; 5a, b; Table A1), which translated to a later date in Turku (Fig. A1a, b). A significant difference in pupation and emergence timing could only be found using the lowest temperature threshold, $2{ }^{\circ} \mathrm{C}$, and even then only for males. It appears that the continental L. monacha was not able to adjust its life cycle timing within one generation to follow optimally the northern summer season. Instead, it attempted to pupate at a similar temperature sum as in its region of origin. The effect was driven to its limit in the northernmost location, where only four continental L. monacha succeeded in pupating at all.

For boreal L. monacha and continental $L$. dispar the picture was more complicated. However, both had a tendency to pupate and emerge at a lower temperature sum in the north than in the south, even more so when using temperature thresholds below $5{ }^{\circ} \mathrm{C}$ (Figs. 2, 5, Table A1). It is possible, that the boreal $L$. monacha population, which struggles at the northern limit of the distribution range of the species, has 
365

366

greater adaptive phenological plasticity than the continental population, facilitating acclimation to varying environments. According to this hypothesis, L. monacha would display high margin plasticity or high leading edge plasticity, as defined by Valladares et al. (2014). However, this would not explain the similar results obtained with continental L. dispar.

Both L. monacha and L. dispar had a tendency towards a shorter pupal period in Turku than in Tharandt. This is likely due to faster pupal development at higher temperatures (Fig. A1). Duration of the pupal period might also simply be linked to the previous results concerning timings of pupation and emergence timing. The progress of both temperature sum and day length is steeper in Turku than in Tharandt (Fig. A1a, b), which could mean that limiting cue values for pupation and emergence follow each other with a shorter interval in Turku, accelerating the pupal development.

The experiment revealed that $L$. dispar was fully able to complete its life cycle in southern Finland. In fact, more L. dispar larvae pupated in Turku than in Tharandt. However, the difference in numbers of emerged adults was negligible (Table 1), which means that pupal mortality was higher in Turku. Interestingly, Lymantria dispar has been observed more frequently in Finland during the past decade than earlier (Insect Observation Data Base). Based on our results, it seems possible that the species has established a local population on the south coast of the country.

Even though no L. dispar adults emerged at Kevo, the larvae were able to complete their development and pupate on B. pubescens ssp. czerepanovii, the same being true for larvae on B. pendula in Tharandt, which indicates that host plant availability would not limit the range expansion of this generalist pest in Fennoscandia, where various Betula species are readily available. However, L. dispar developed slightly faster on $Q$. robur than on B. pendula, and the pupae of larvae reared on $Q$. robur were heavier. All three tree species are listed as preferred host plants for L. dispar by Lechowicz \& Mauffette (1986), though the specific subspecies of $B$. pubescens is not mentioned on the list. Although we considered the two birch species similar enough for relevant comparisons, there does remain a possibility that our results concerning the differences between $L$. dispar at Kevo and in Tharandt are, at least partly, 
390

391

392

393

394

395

396

397

398

399

400

401

402

403

404

405

406

407

408

409

410

411

412

413

414

415

influenced by the host plant. However, we strongly doubt that host plant species has influenced the major conclusion that L. dispar is able to finish its life cycle in Tharandt and Turku but not in Kevo.

The data contained certain unexpectedly short pupal periods of both L. monacha and L. dispar. The shortest pupal period observed was only 5.5 days (boreal L. monacha in Turku), and a total of 38 pupae had pupal periods below 10 days, most of them observed in Turku. Generally pupal periods of $L$. monacha and L. dispar are reported to be about two weeks (Campbell 1967), which is clearly longer than that reported for most test groups here (Fig. 4). The effect may, at least partly, be explained by the longer day in Turku accelerating the pupal development (Bogach et al. 1966, Kireeva 1969). The method of determining the date of pupation (see Chapter 2.3) may have led to an error of 3-3.5 days in four cases and 2.5 days in eight additional cases, with the error being maximally 2 days in all other cases, but this was as more likely to falsely lengthen rather than to shorten the pupal period.

Our study setup was not designed to reveal any possible developmental temperature sum thresholds for the studied species. Instead, the temperature sum as a response variable enabled comparison of the summer seasons at our three field sites, giving biologically more meaningful measurements for "earlier" or "later" than mere calendar dates would have allowed. Day length, instead of temperature, is estimated to be the most important environmental cue for the timing of phenology in temperate insects (de Wilde 1962, Bale et al. 2002). Previous literature confirms that day length also plays a role also for at least $L$. dispar (Bogach et al. 1966, Leonard 1968, Kireeva 1969, Denlinger et al. 1992). However, almost all previous research on life cycle timing of our study species concerns diapause induction and termination, which occurs in winter during the pharate-larval stage in eggs (Tauber et al. 1990, Gray et al. 1991, Keena 1996, Patterson et al. 1999, the latter, however, listing the photoperiod as irrelevant for L. dispar diapause control). The triggers relevant for other life cycle events are not well understood. There were differences between the summer seasons at our field sites not only in the temperatures, but also in day length (Fig. A1). It is conceivable that these differences of several hours could hamper the range expansion of L. monacha and L. dispar across latitudes and require special adaptations or adaptive phenotypic plasticity in the same way as temperature differences do. 
416 We conclude that, while neither L. monacha nor L. dispar were able to fully complete their life cycle in

417 northernmost Finland, both local and continental L. monacha strains as well as continental L. dispar, a

418 species not yet established in Finland, performed well when reared outdoors on the south coast of the

419 country. Intrapopulation differences in life cycle timing, possibly indicative of adaptive phenotypic

420 plasticity facilitating a fast reaction to new environmental conditions, were clearer for continental $L$.

421 dispar and boreal L. monacha than for continental L. monacha. Interpopulation differences in life cycle

422 timing and pupal mass were revealed between boreal and continental L. monacha, possibly pointing to

423 an adaptation to local environmental conditions. The three host plants used for L. dispar, Q. robur, B.

424 pendula and $B$. pubescens ssp. czerepanovii all proved suitable for the species, revealing that host plant 425 availability would not limit range expansion of $L$. dispar in northern Fennoscandia.

\section{Acknowledgements}

428 We warmly thank Tommi Andersson, Marjo Anttila, Stefania Fält, Maija Laaksonen, Michal Miškeje, 429 Otto Saikkonen, Dagmar Schulz and Hille Sundermeier for their invaluable help and long workdays at 430 the three field sites as well as Ingo Brunk, Kalevi Fält, Carola Karlsson-Fält and Tarja Pajari for their 431 patient help with collecting female moths and eggs for the study. We are grateful to Elizabeth Nyman 432 for reviewing the language of this manuscript and to Dirk Junkuhn, Elina Vainio and the staff and 433 colleagues at the TU Dresden Department of Forest Sciences for providing assistance, facilities and 434 equipment for the experiments. We also thank the anonymous reviewers for constructive suggestions to improve the manuscript. The Finnish Meteorological Institute and the Chair of Meteorology at the 436 Technische Universität Dresden provided us with meteorological data. This study was funded by the 437 Finnish Cultural Foundation (grant to J.F-N.). 


\section{References}

438 Ammunét, T., Klemola, T., and Saikkonen, K. 2011. Impact of host plant quality on

439 geometrid moth expansion on environmental and local population scales. Ecography 34(5):

440 848-855. doi: 10.1111/j.1600-0587.2011.06685.x

441 Ammunét, T., Kaukoranta, T., Saikkonen, K., Repo, T., and Klemola, T. 2012. Invading and

442 resident defoliators in a changing climate: cold tolerance and predictions concerning extreme

443 winter cold as a range-limiting factor. Ecol. Entomol. 37(3): 212-220. doi: 10.1111/j.1365-

$444 \quad 2311.2012 .01358 . x$

445

446

447

448

449

450

451

452

453

454

455

456

457 van Asch, M., and Visser, M.E. 2007. Phenology of forest caterpillars and their host trees: the importance of synchrony. Annu. Rev. Entomol. 52: 37-55. doi:

10.1146/annurev.ento.52.110405.091418

Bale, J.S., Masters, G.J., Hodkinson, I. D., Awmack, C., Bezemer, T.M., Brown, V.K., Butterfield, J., Buse, A., Coulson, J.C., Farrar, J., Good, J.E.G., Harrington, R., Hartley, S., Jones, T.H., Lindroth, R.L., Press, M.C., Symrnioudis, I., Watt, A.D., and Whittaker, J.B. 2002. Herbivory in global climate change research: direct effects of rising temperature on insect herbivores. Glob. Change Biol. 8 (1): 1-16. doi: 10.1046/j.1365-2486.2002.00451.x

Bejer, B., 1988. The nun moth in European spruce forests. In Dynamics of forest insect populations. Patterns, causes, implications. Edited by A.A. Berryman. Plenum Press, New York and London. pp. 211-231.

Björkman, C., and Niemelä, P. (editors). 2015. Climate Change and Insect Pests. CABI Publishing. $291 \mathrm{p}$. 
458

459

460

461

462

463

464

465

466

467

468

469

470

471

472

473

474

475

476

Bogach, A.V., Zolotoverkha, I.M., and Kirichenko, O.I. 1966. The importance of light and temperature in the reproduction of some species of Lepidoptera (Porthetria dispar L. and Bombyx mori L.). Dopov. Akad. Nauk Ukr. 6:825-827. [In Ukrainian, English summary.]

Buse, A., and Good, J. 1996. Synchronization of larval emergence in winter moth

(Operophtera brumata L.) and budburst in pedunculate oak (Quercus robur L.) under simulated climate change. Ecol. Entomol. 21(4): 335-343. doi: 10.1046/j.1365-

2311.1996.t01-1-00001.x

Campbell, R.W. 1967. The analysis of numerical change in gypsy moth populations. Forest Sci., Monograph 13 (Supplement to Number 3): a0001-z0001 (1).

Danks H.V. 1987. Insect dormancy: An Ecological Perspective. Biological Survey of Canada Monograph Series, No 1. Entomological Society of Canada, Ottawa, Canada. 439 p.

Denlinger, D.L., Lee, R.E., Yocum, G.D., and Kukal, O. 1992. Role of chilling in the acquisition of cold tolerance and the capacitation to express stress proteins in diapausing pharate larvae of the gypsy moth, Lymantria dispar. Arch. Insect Biochem. Physiol. 21(4): 271-280. doi: 10.1002/arch.940210404

European Environment Agency 2012. Biogeographic regions in Europe. [online] Available from e001d623865845e3ba8f6bd2f28a5ed3. European Environment Agency, Copenhagen, Denmark. [accessed 3 November 2016]

Forbush, E. H., and Fernald, C. H. 1896. The gypsy moth. Wright and Potter, Boston. 495 p. 
477 Foster, J.R., Townsend, P.A., and Mladenoff, D.J. 2013. Mapping asynchrony between gypsy

478 moth egg-hatch and forest leaf-out: Putting the phenological window hypothesis in a spatial

479 context. For. Ecol. Manage. 287: 67-76. doi: 10.1016/j.foreco.2012.09.006

480 Gerding, G. 2016. Finden Sie hier die Zeiten des Sonnenaufgangs und des Sonnenuntergangs

481 für jeden beliebigen Ort [online]. Available from http://www.sonnenaufgang-

482 sonnenuntergang.de [accessed 26 August 2016].[in German.]

483 Gilbert, N. 1984. Control of fecundity in Pieris rapae: I. The problem. J. Anim. Ecol. 53(2):

484 581-588. doi: $10.2307 / 4536$

485 Gray, D.R., Logan, J.A., Ravlin, F.W., and Carlson, J.A. 1991. Toward a model of gypsy

486 moth egg phenology: using respiration rates of individual eggs to determine temperature-time

487 requirements of prediapause development. Environ. Entomol. 20(6):1645-1652. doi:

$488 \quad 10.1093 / \mathrm{ee} / 20.6 .1645$

489 Gray, D.R.. Hitchhikers on trade routes: A phenology model estimates the probabilities of 490 gypsy moth introduction and establishment. Ecol. Appl. 20(08): 2300-2309. doi: 10.1890/09$491 \quad 1540.1$

492 Grönblom, T., and Suomalainen, E. 1950. Über das Vorkommen der Nonne, Lymantria 493 monacha L. in Finnland. Ann. Ent. Fennici 16: 178-181. [in German.]

494 Hindle, B. J., Kerr, C. L., Richards, S. A., and Willis, S. G. 2015. Topographical variation 495 reduces phenological mismatch between a butterfly and its nectar source. J. Insect Conserv.

496 19(2): 227-236. doi:10.1007/s10841-014-9713-x 
497 Honěk, A. 1993. Intraspecific variation in body size and fecundity in insects: a general 498 relationship. Oikos 66(3): 483-492.

499 Hough, J.A., and Pimentel, D. 1978. Influence of host foliage on development, survival, and 500 fecundity of the gypsy moth. Environ. Entomol.7(1): 97-102.

501 Insect Observation Data Base (Hyönteistietokanta) [online] Available from

502 http://hyonteiset.luomus.fi/insects/main/EntDatabase.html. Finnish Museum of Natural

503 History, Helsinki, Finland. [accessed 26 August 2016] [In Finnish.]

504 Jankovic, M., Zecevic, D., and Vojnovic, V. 1960. Races of the gipsy moth in Yugoslavia

505 (Report for 1959). Zaštita Bilja 56: 99-107. [In Serbo-Croatian, English summary.]

506 Jepsen, J.U., Hagen, S.B., Ims, R.A., and Yoccoz, N.G. 2008. Climate change and outbreaks

507 of the geometrids Operophtera brumata and Epirrita autumnata in subarctic birch forest:

508 evidence of a recent outbreak range expansion. J. Anim. Ecol. 77(2): 257-264. doi:

$509 \quad 10.1111 / \mathrm{j} .1365-2656.2007 .01339 . x$

510 Jepsen, J.U., Kapari, L., Hagen, S.B., Schott, T., Vindstad, O.P.L., Nilssen, A.C., and Ims,

511 R.A. 2011. Rapid northwards expansion of a forest insect pest attributed to spring phenology

512 matching with sub-Arctic birch. Glob. Change Biol. 17(6): 2071-2083. doi: 10.1111/j.1365-

$513 \quad 2486.2010 .02370 . x$

514 Kaitaniemi, P., Scheiner, A., Klemola, T., and Ruohomäki, K. 2012. Multi-objective

515 optimization shapes ecological variation. Proc. R. Soc. B 279 (1729): 820-825. doi:

$516 \quad 10.1098 /$ rspb.2011.1371 
517 Karolewski, P., Grzebyta, J., Oleksyn, J., and Giertych, M. J. 2007. Effects of temperature on

518 larval survival rate and duration of development of Lymantria monacha (L.) on needles of

519 Pinus sylvestris (L.) and of L. dispar (L.) on leaves of Quercus robur (L.). Pol. J. Ecol. 55(3):

$520595-600$.

521 Keena, M.A. 1996. Comparison of the hatch of Lymantria dispar (Lepidoptera: Lymantriidae)

522 eggs from Russia and the United States after exposure to different temperatures and durations

523 of low temperature. Ann. Entomol. Soc. Am. 89(4):564-572. doi: 10.1093/aesa/89.4.564

524 Keena, M.A. 2003. Survival and Development of Lymantria monacha (Lepidoptera:

525 Lymantriidae) on North American and Introduced Eurasian Tree Species. J. Econ. Entomol.

526 96(1): 43-52. doi: 10.1093/jee/96.1.43

527 Kenward, M.G., and Roger, J.H. 1997. Small sample inference for fixed effects from

528 restricted maximum likelihood. Biometrics 53:983-997. Available from

529 http://people.umass.edu/bioep740/topics/biometrics-1997-kenward.pdf [accessed 3 November $5302016]$.

531 Kireeva, I. M. 1969 Peculiarities of the Porthetria dispar L. pupal development under

532 different photothermal conditions. Vestnik Zoologii 1:86-88. [In Ukrainian, English

533 summary.]

534 Lechowicz, M.J., and Mauffette, Y. 1986. Host preferences of the gypsy moth in eastern

535 North American versus European forests. Revue d'entomologie du Quebec. 31(1), 43-51. 
536 Leinonen, R., Pöyry, J., Söderman, G., and Tuominen-Roto, L. 2016. Suomen

537 yöperhosseuranta (Nocturna) 1993-2012. Suomen ympäristökeskuksen raportteja 15/2016.

538 Suomen ympäristökeskus, Helsinki, Finland. [In Finnish.]

539 Leonard, D.E. 1966. Differences in development of strains of the gypsy moth, Porthetria

540 dispar (L.). 1966. Bulletin of the Connecticut Agricultural Experiment Station, New Haven.

541 No. 680.

542 Leonard, D.E. 1968. Diapause in the gypsy moth. J. Econ. Entomol. 61(3): 596-598. doi:

$543 \quad 10.1093 /$ jee/ 61.3 .596

544 Leonard, D.E. 1974. Recent developments in ecology and control of the gypsy moth. Annu.

545 Rev. Entomol. 19(1):197-229. doi: 10.1146/annurev.en.19.010174.001213

546 Liebhold, A.M., Halverson, J.A., and Elmes, G.A. 1992. Gypsy moth invasion in North

547 America: a quantitative analysis. J. Biogeogr. (5):513-520.

548 Liebhold, A.M., Elkinton, J., Williams, D., and Muzika, R.M. 2000. What causes outbreaks of 549 the gypsy moth in North America? Popul. Ecol. 42(3):257-266. doi: 10.1007/PL00012004

550 Littell, R.C., Milliken, G.A., Stroup, W.W., Wolfinger, R.D., and Schabenberger, O. 2006.

551 SAS ${ }^{\circledR}$ for mixed models, $2^{\text {nd }}$ edition, SAS Institute Inc., Cary, NC, USA

552 Majunke, C., Möller, K., and Funke, M. 2004. Waldschutz-Merkblatt 52 - Die Nonne. 3 edn.

553 Eberswalde und Finkenkrug: Landesforstanstalt Eberswalde. Eberswalde, Germany. 24 p. 
554 Memmott, J., Craze, P.G., Waser, N.M., and Price, M.V. 2007. Global warming and the 555 disruption of plant-pollinator interactions. Ecol. Lett. 10(8): 710-717. doi: 10.1111/j.1461$556 \quad 0248.2007 .01061 . x$

557 Nylin, S.,and Gotthard, K. 1998. Plasticity in life-history traits. Annu. Rev. Entomol.43:63558 83. doi: 10.1146/annurev.ento.43.1.63

559 Parmesan, C., Ryrholm, N., Stefanescu, C., Hill, J.K., Thomas, C.D., Descimon, H., Huntley, 560 B., Kaila, L., Kullberg, J., Tammaru, T., Tennent, W.J., Thomas, J.A., and Warren, M. 1999.

561 Poleward shifts in geographical ranges of butterfly species associated with regional warming. 562 Nature 399(6736): 579-583. doi:10.1038/21181

563 Patterson, D.T., Westbrook, J.K., Joyce, R.J.V., Lingren, P.D., and Rogasik, J. 1999. Weeds, 564 insects, and diseases. Clim. Change 43(4): 711-727. doi: 10.1023/A:1005549400875

565 Saikkonen, K., Taulavuori, K., Hyvönen, T., Gundel, P.E., Hamilton, C.E., Vänninen, I., 566 Nissinen, A., and Helander, M. 2012. Climate change-driven species' range shifts filtered by 567 photoperiodism. Nat. Clim. Change 2(4), 239-242. doi:10.1038/nclimate1430

568 Stroup, W.W. 2013. Generalized linear mixed models: modern concepts, methods and 569 application, CRC Press, Boca Raton, FL, USA

570 Tammaru, T., and Haukioja, E. 1996. Capital breeders and income breeders among

571 Lepidoptera: consequences to population dynamics. Oikos 77(3):561-564. doi:

$572 \quad 10.2307 / 3545946$ 
573 Tauber, M.J., Tauber, C.A., Ruberson, J.R., Tauber, A.J., and Abrahamson, P. 1990.

574 Dormancy in Lymantria dispar (Lepidoptera: Lymantriidae): analysis of photoperiodic and 575 thermal responses. Ann. Entomol. Soc. Am. 83(3): 494-503. doi: 10.1093/aesa/83.3.494

576 Valladares, F., Matesanz, S., Guilhaumon, F., Araújo, M.B., Balaguer, L., Benito-Garzón, M.,

577 Cornwell W., van Kleunen, M., Naya D.E., Nicotra, A.B., Poorter, H., and Zavala, M.A.

578 2014. The effects of phenotypic plasticity and local adaptation on forecasts of species range

579 shifts under climate change. Ecol. Lett. 17(11): 1351-1364. doi: 10.1111/ele.12348

580 Valtonen, A., Ayres, M.P., Roininen, H., Pöyry, J., and Leinonen, R. 2011. Environmental 581 controls on the phenology of moths: predicting plasticity and constraint under climate change. 582 Oecologia 165(1): 237-248. doi:10.1007/s00442-010-1789-8

583 Vanhanen, H., Veteli, T.O., Päivinen, S., Kellomäki, S., and Niemelä, P. 2007. Climate 584 change and range shifts in two insect defoliators: gypsy moth and nun moth - a model study. 585 Silva Fenn. 41(4): 621-638. Available from 586 http://www.metla.fi/silvafennica/full/sf41/sf414621.pdf [accessed 26 August 2016].

587 Visser, M.E., and Holleman, L.J., 2001. Warmer springs disrupt the synchrony of oak and 588 winter moth phenology. Proc. R. Soc. B 268(1464): 289-294.

589 Wie, J., Luo, Y.Q., Shi, J., Wang, D.P. and Shen, S.W., 2014. Impact of temperature on 590 postdiapause and diapause of the Asian gypsy moth, Lymantria dispar asiatica. J. Insect Sci.

$591 \quad 14$ (5). doi: 10.1673/031.014.05 
592 de Wilde, J. 1962. Photoperiodism in insects and mites. Annu. Rev. Entomol. 7(1): 1-26. doi:

593 10.1146/annurev.en.07.010162.000245

594 Yasyukevich, V.V., Titkina, C.N., Davidovich, E.A., and Yasyukevich, N.V. 2015. Changes

595 in range boundaries of the gypsy moth and the nun moth (Lymantria dispar, L. monacha,

596 Lymantriidae, Lepidoptera) due to the global warming: a model approach. Entomol. Rev.

597 95(8): 1144-1148. doi:10.1134/S0013873815080229 


\section{Tables}

599 Table 1. The number of egg batches, eggs, pupae and adult moths per species and host plant 600 assigned for the three field sites. Each batch consisted of 16 eggs, divided into two vials (later 601 two mesh bags). Individuals and single measurement values excluded from analyses (see 602 Chapter 2.4) are not shown in the table - the discrepancy between the number of pupae used 603 for the pupation time and pupal mass analyses is explained by cases where the pupation date 604 was available but the pupal mass was not.

\begin{tabular}{|c|c|c|c|c|c|}
\hline & & & & & \\
\hline & Species and & & number of & for analysis & for \\
\hline Field site & population of origin & Host plant & batches/eggs & (pupation/mass) & analysis \\
\hline Tharandt & L. dispar $\mathrm{DE}$ & Birch & $7 / 112$ & $57 / 57$ & 41 \\
\hline $50^{\circ} 58^{\prime} \mathrm{N}$ & L. dispar $\mathrm{DE}$ & Oak & $7 / 112$ & $61 / 61$ & 37 \\
\hline $13^{\circ} 50^{\prime} \mathrm{E}$ & L. monacha DE & Pine & $7 / 112$ & $41 / 40$ & 28 \\
\hline & L. monacha S. FI & Pine & $5 / 80$ & $56 / 55$ & 50 \\
\hline Turku & L. dispar $\mathrm{DE}$ & Oak & $7 / 112$ & $81 / 77$ & 42 \\
\hline $60^{\circ} 26^{\prime} \mathrm{N}$ & L. monacha DE & Pine & $7 / 112$ & $21 / 20$ & 13 \\
\hline $22^{\circ} 10^{\prime} \mathrm{E}$ & L. monacha S. FI & Pine & $5 / 80$ & $41 / 32$ & 20 \\
\hline Kevo & L. dispar $\mathrm{DE}$ & Birch & $7 / 112$ & $24 / 20$ & 0 \\
\hline $69^{\circ} 44^{\prime} \mathrm{N}$ & L. monacha DE & Pine & $7 / 112$ & $0 / 0$ & 0 \\
\hline $27^{\circ} 00^{\prime} \mathrm{E}$ & L. monacha S. FI & Pine & $5 / 80$ & $21 / 21$ & 0 \\
\hline
\end{tabular}

605

606 
607 Figures and figure captions

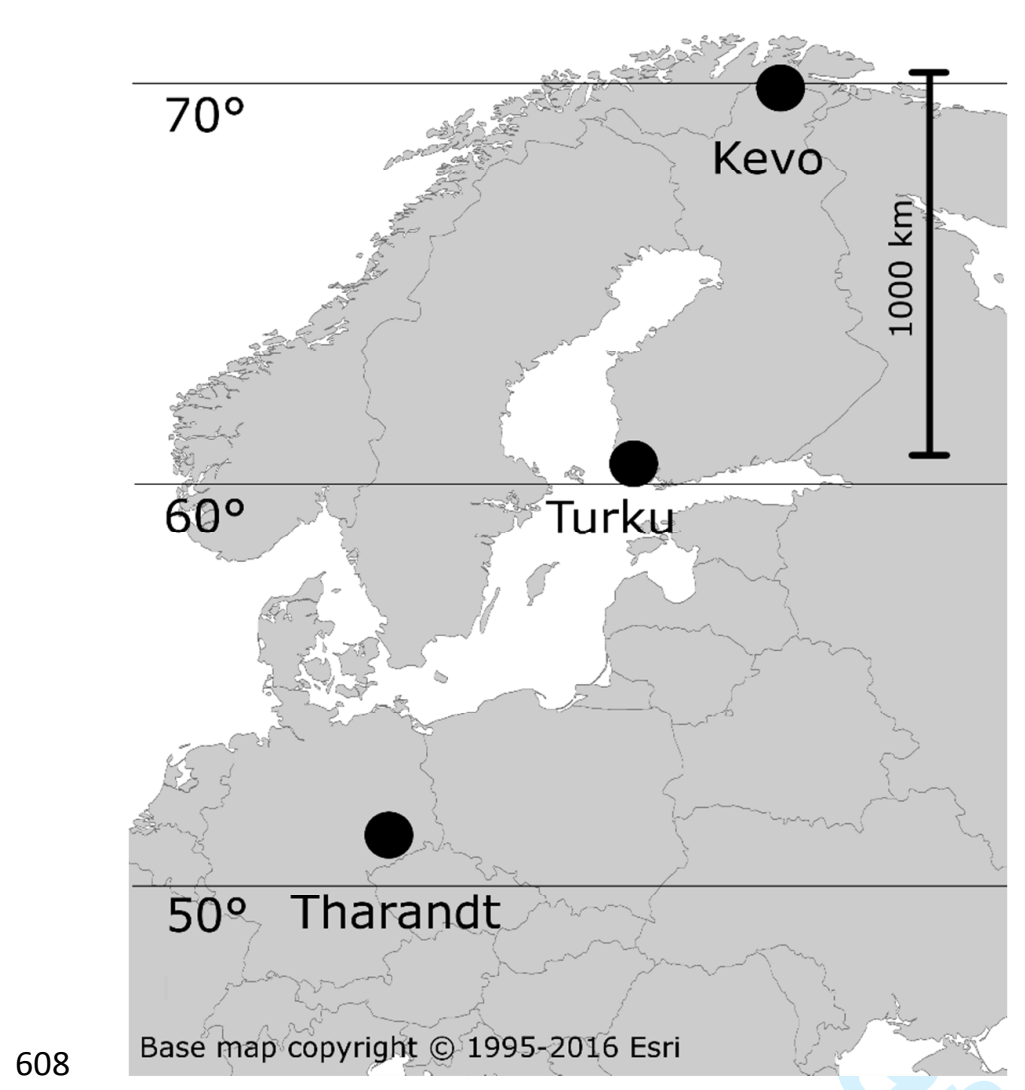

609 Fig. 1. Locations of the three field sites. 


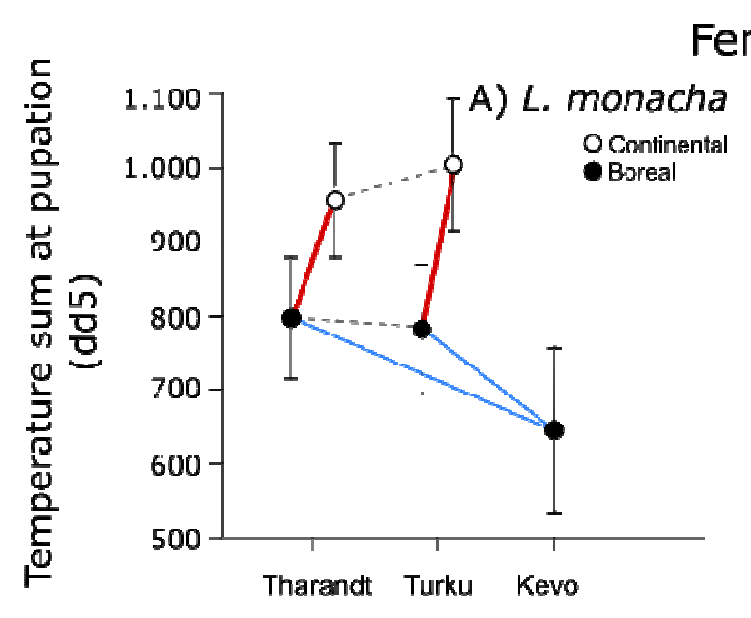

Females
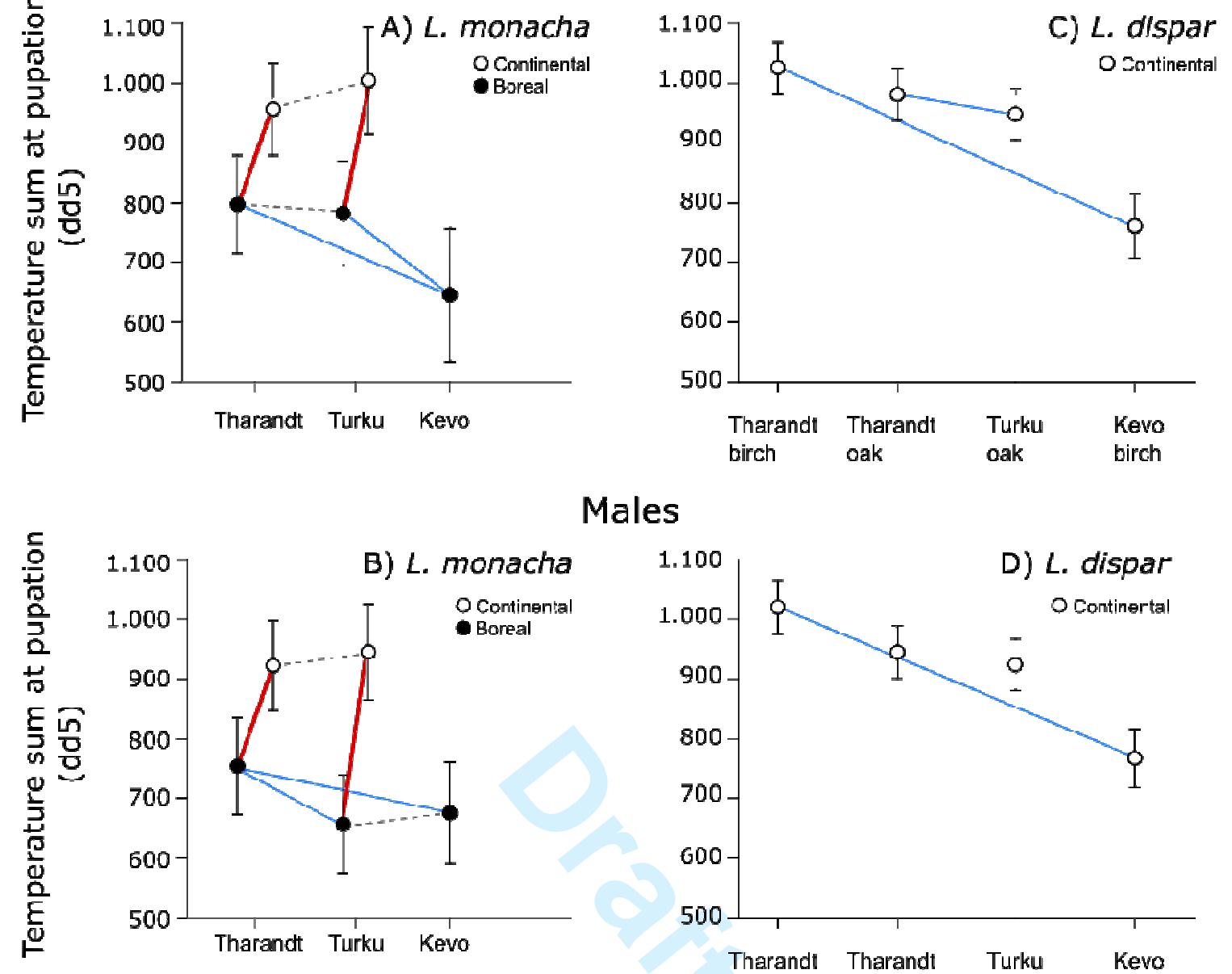

Males

\section{Field site}

611 Fig. 2 Model-derived marginal mean estimates with 95\% confidence limits for accumulated

612 temperature sums (dd5) at pupation of L. monacha (A, B) and L. dispar (C, D). A priori

613 contrasts marking pairwise differences between the test groups are displayed with lines: grey

614 dashed lines (not statistically significant), thick red lines (significant interpopulation

615 differences) and thin blue lines (significant intrapopulation differences). Exact statistical

616 values are presented in Table A1. 


\section{Females}
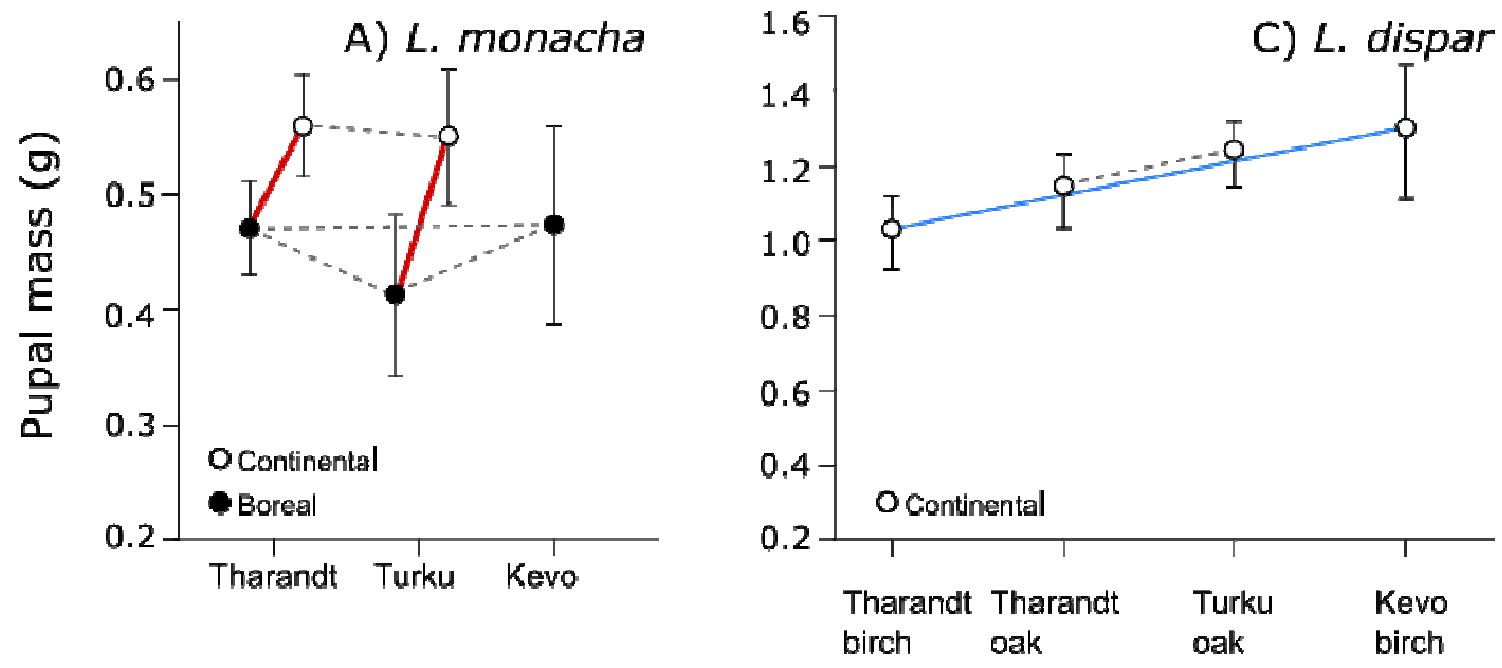

\section{Males}
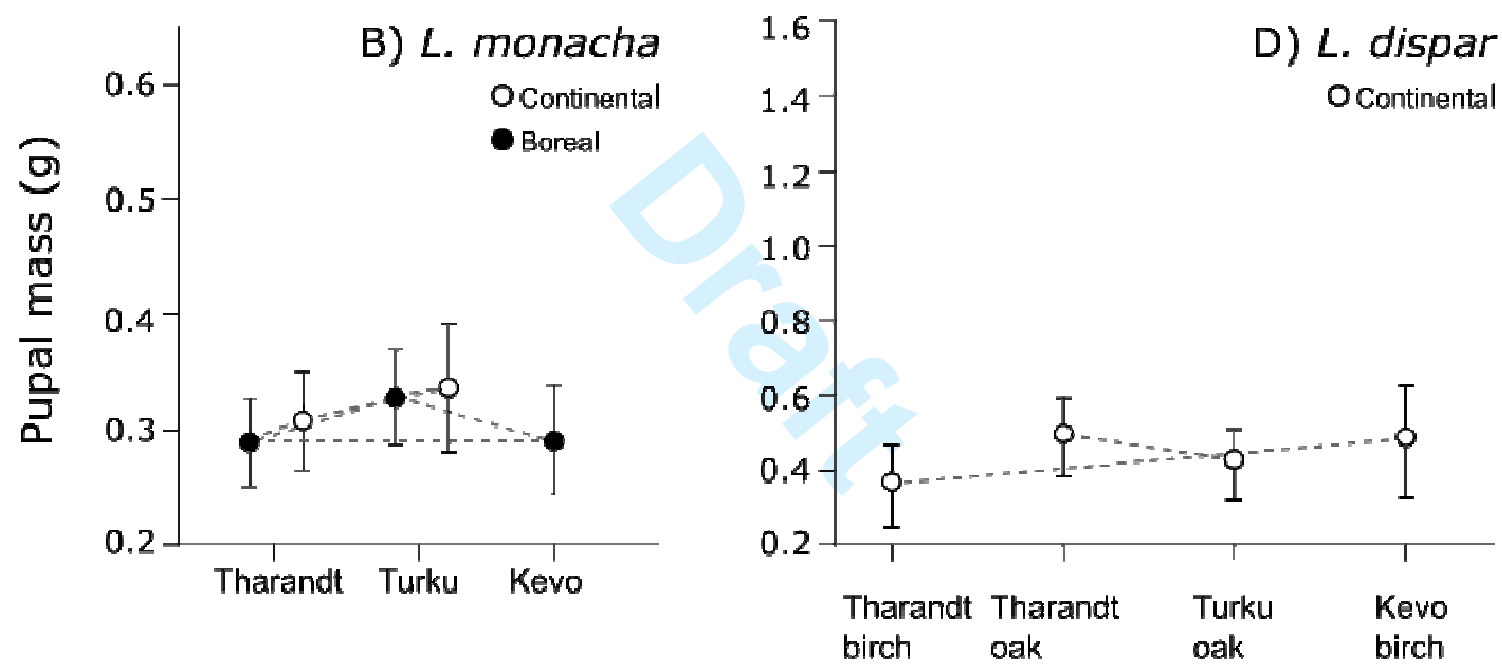

Fig. 3 Model-derived marginal mean estimates with 95\% confidence limits for pupal mass (grams) of L. monacha (A, B) and L. dispar (C, D). A priori contrasts marking pairwise differences between test groups are displayed with lines: grey dashed lines (not statistically significant), thick red lines (significant interpopulation differences) and thin blue lines (significant intrapopulation differences). Exact statistical values are presented in Table A1. Note the different scales on the y-axis. 


\section{Females}
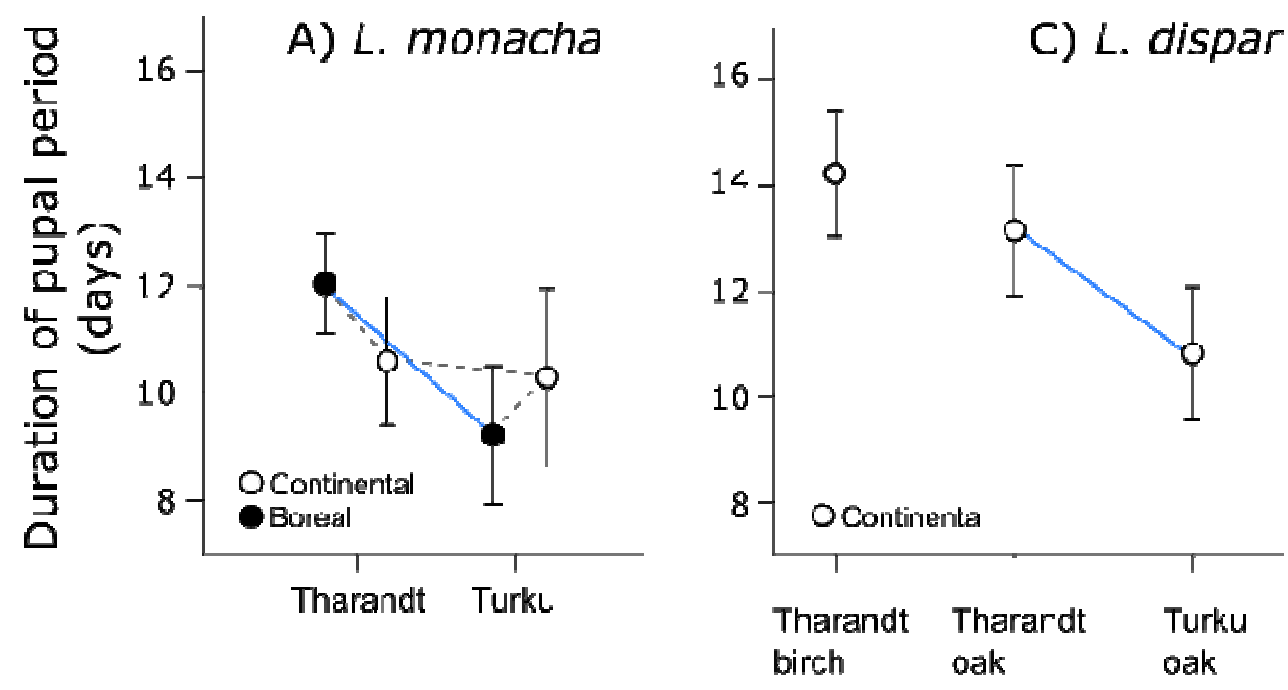

Males
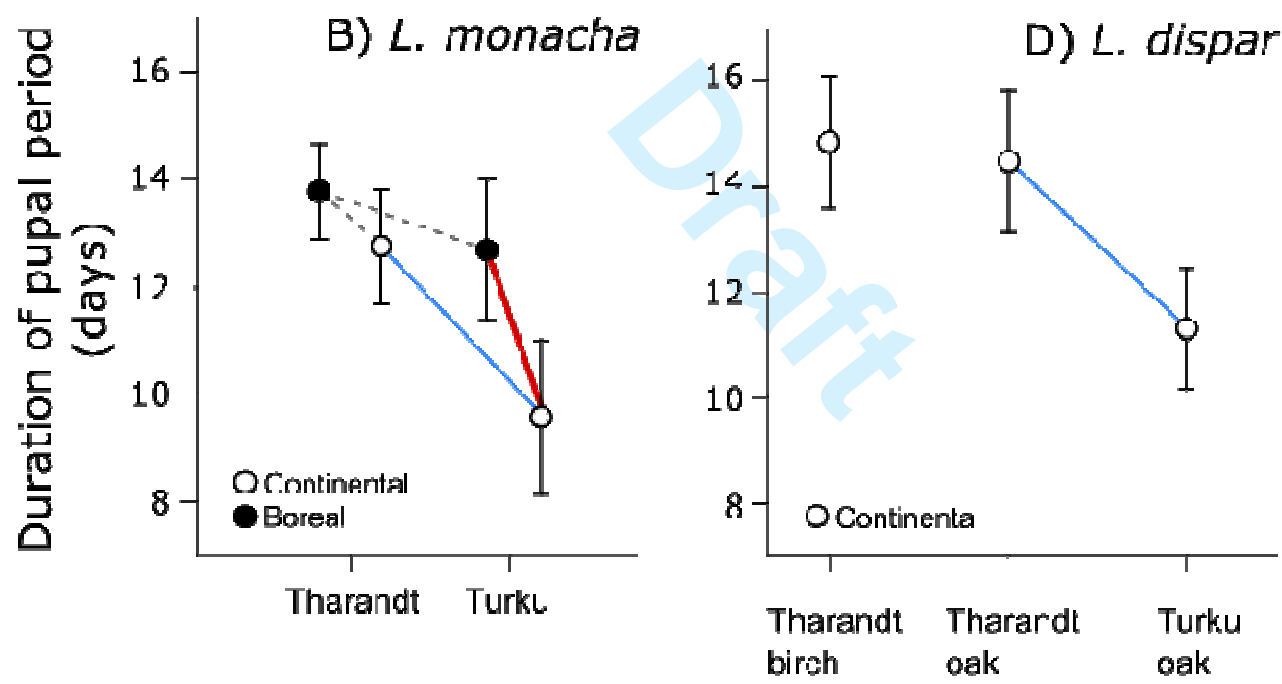

627 Fig. 4 Model-derived marginal mean estimates with 95\% confidence limits for the duration of 628 the pupal period (days) of L. monacha (A, B) and L. dispar (C, D). A priori contrasts marking 629 pairwise differences between the test groups are displayed with lines: grey dashed lines (not 630 statistically significant), thick red lines (significant interpopulation differences) and thin blue 631 lines (significant intrapopulation differences). Exact statistical values are presented in Table 632 A1. 


\section{Females}
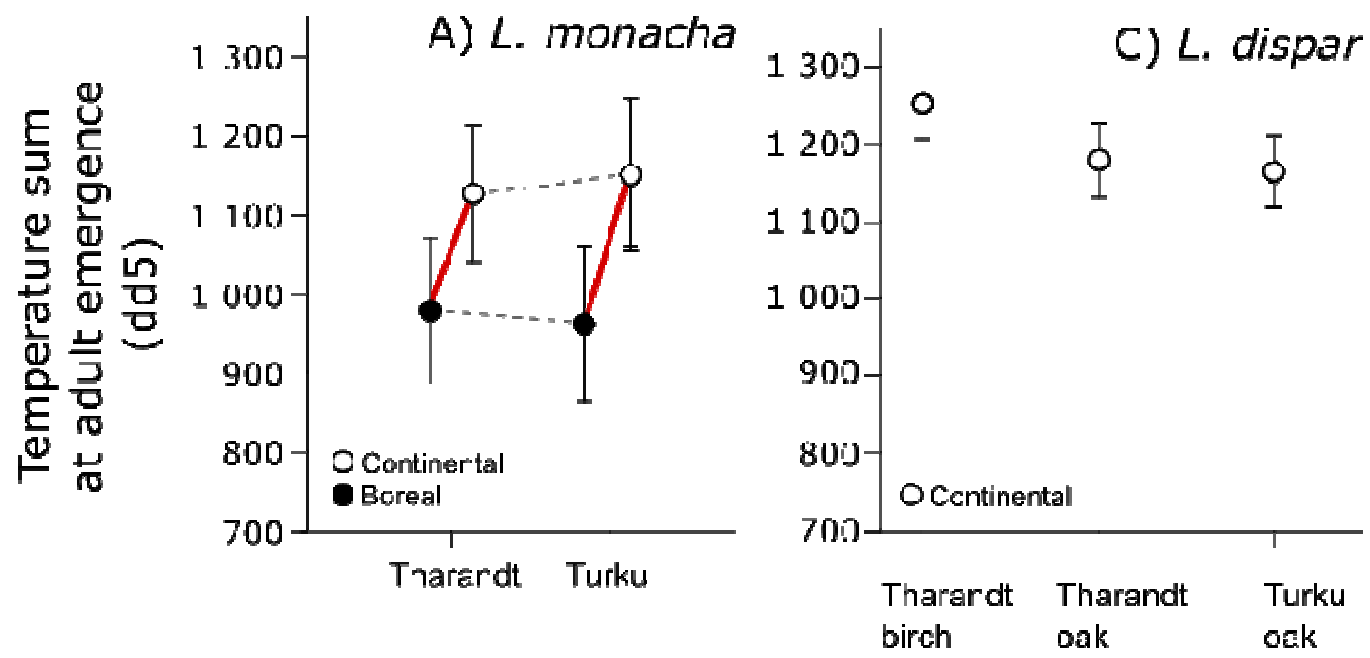

Males

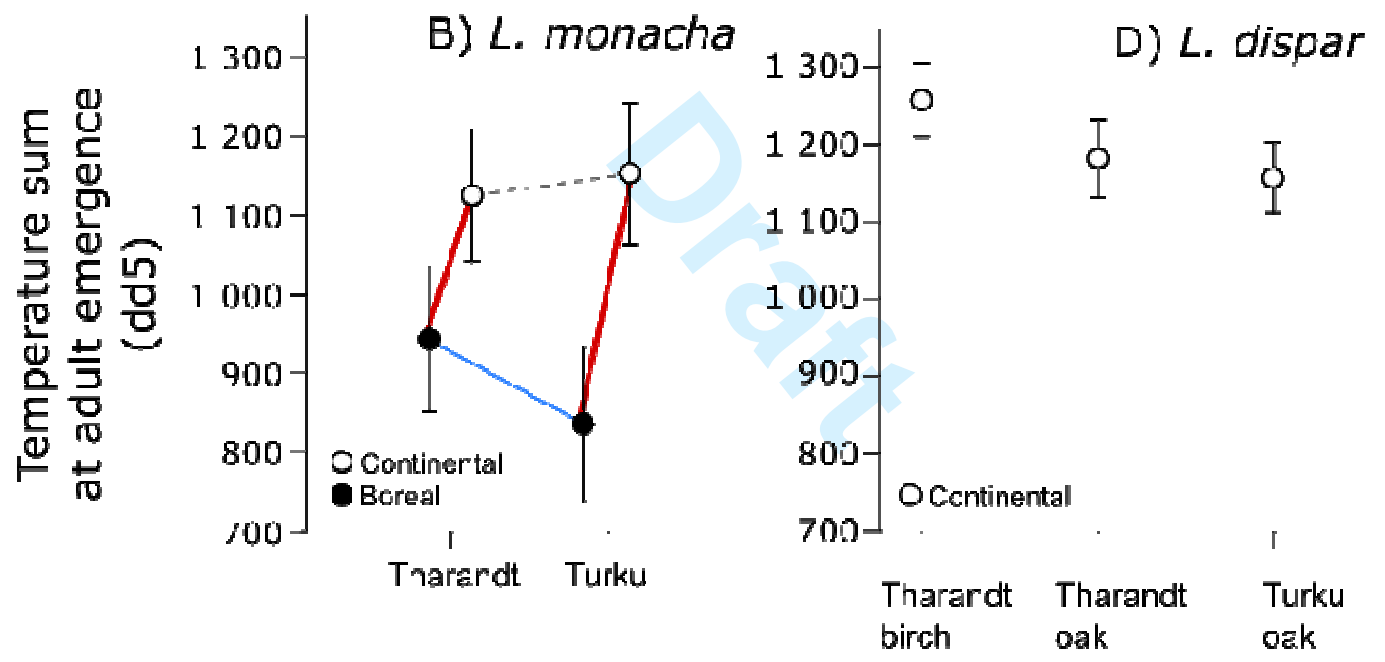

634 Fig. 5 Model-derived marginal mean estimates with 95\% confidence limits for accumulated

635 temperature sums (dd5) at adult emergence of L. monacha (A, B) and L. dispar (C, D). A

636 priori contrasts marking pairwise differences between the test groups are displayed with lines:

637 grey dashed lines (not statistically significant), thick red lines (significant interpopulation

638 differences) and thin blue lines (significant intrapopulation differences). Exact statistical

639 values are presented in Table A1. 
641 Appendix
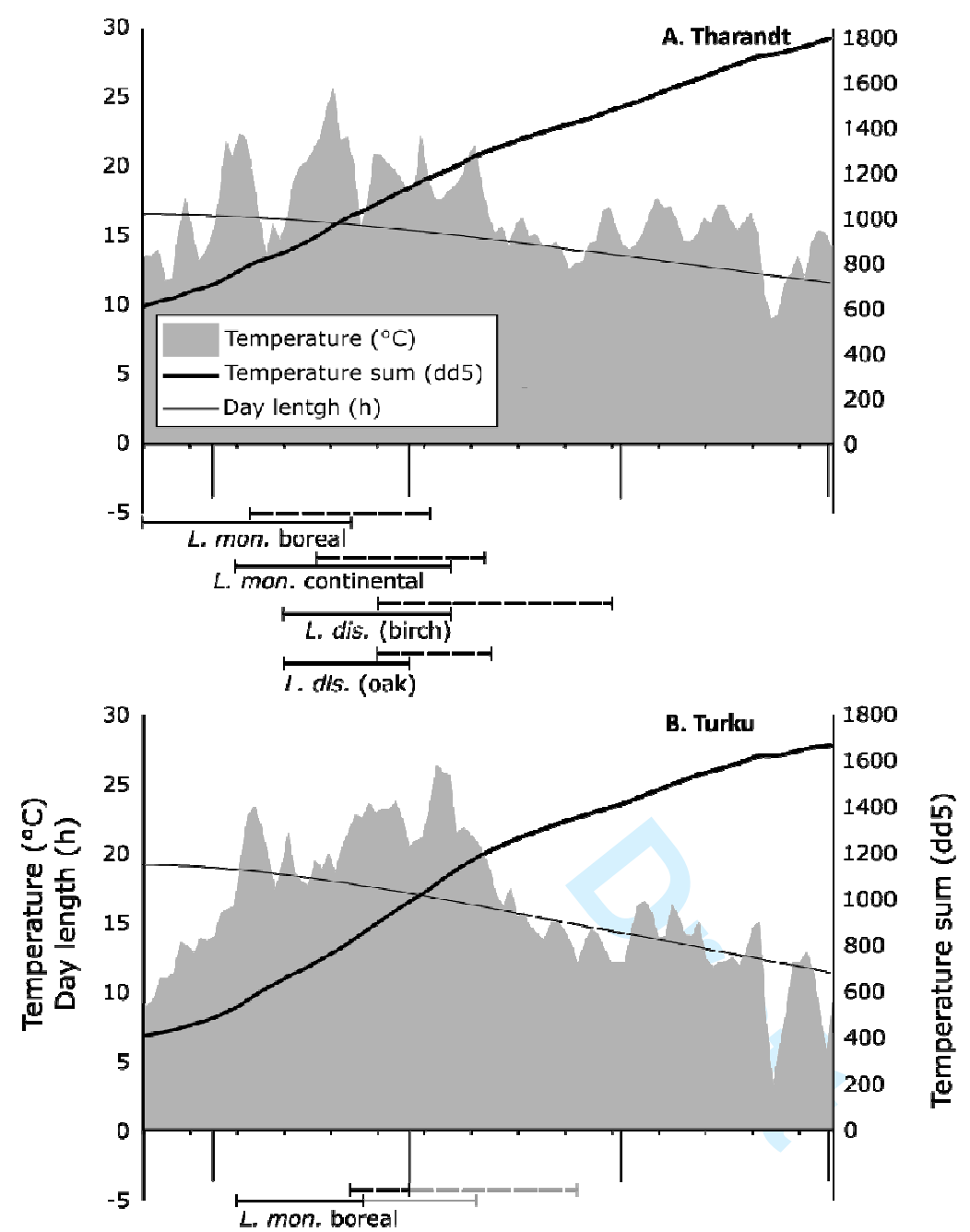

L. mon. continental
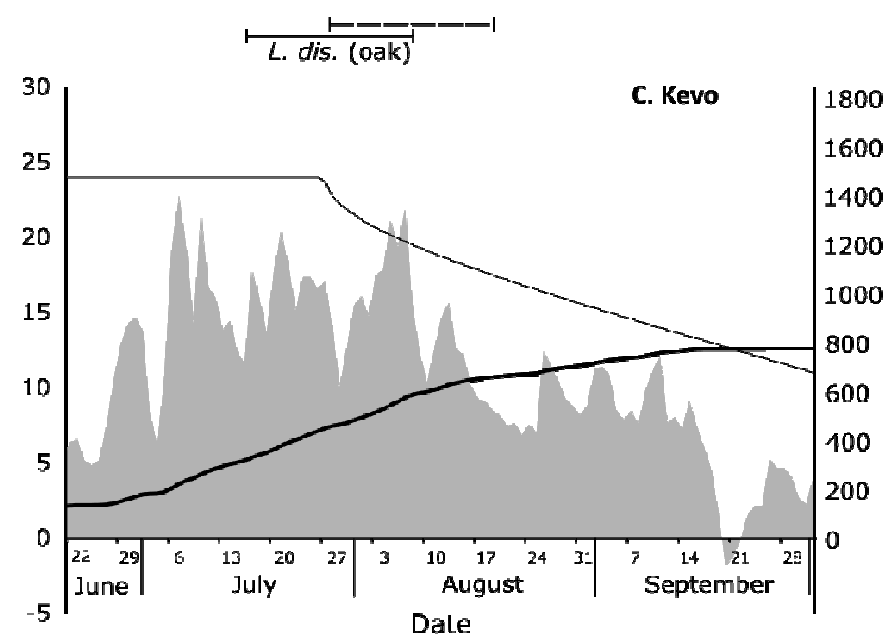

642

L. mon. boreál 
644 Fig. A1The phenology of L. monacha and L. dispar at the three field sites compared to local 645 temperatures, temperature sums accumulated above $5^{\circ} \mathrm{C}$ and day length. The lines below 646 each graph correspond with the pupation period (solid line) and adult emergence (dashed line)

647 of the test groups reared at each site. In Turku, there were two boreal L. monacha larvae that 648 pupated considerably later than the rest and consequently one adult moth that emerged very 649 late. The lines displaying L. monacha phenology in Turku have therefore been extended in 650 grey to include these outliers. Removing these from the data would not have crucially 651 changed the statistical significance of any of the results.

652

653 Table A1. A priori contrast statistics for pairwise comparisons of test groups. Statistically 654 significant $\mathrm{p}$-values in bold. Notice, that intrapopulation differences here simply refer to 655 differences between test groups of individuals originating from the same population but 656 reared in different location and interpopulation differences correspondingly to differences 657 between test groups of individuals of different origins but reared in the same location.

658 
Canadian Journal of Forest Research

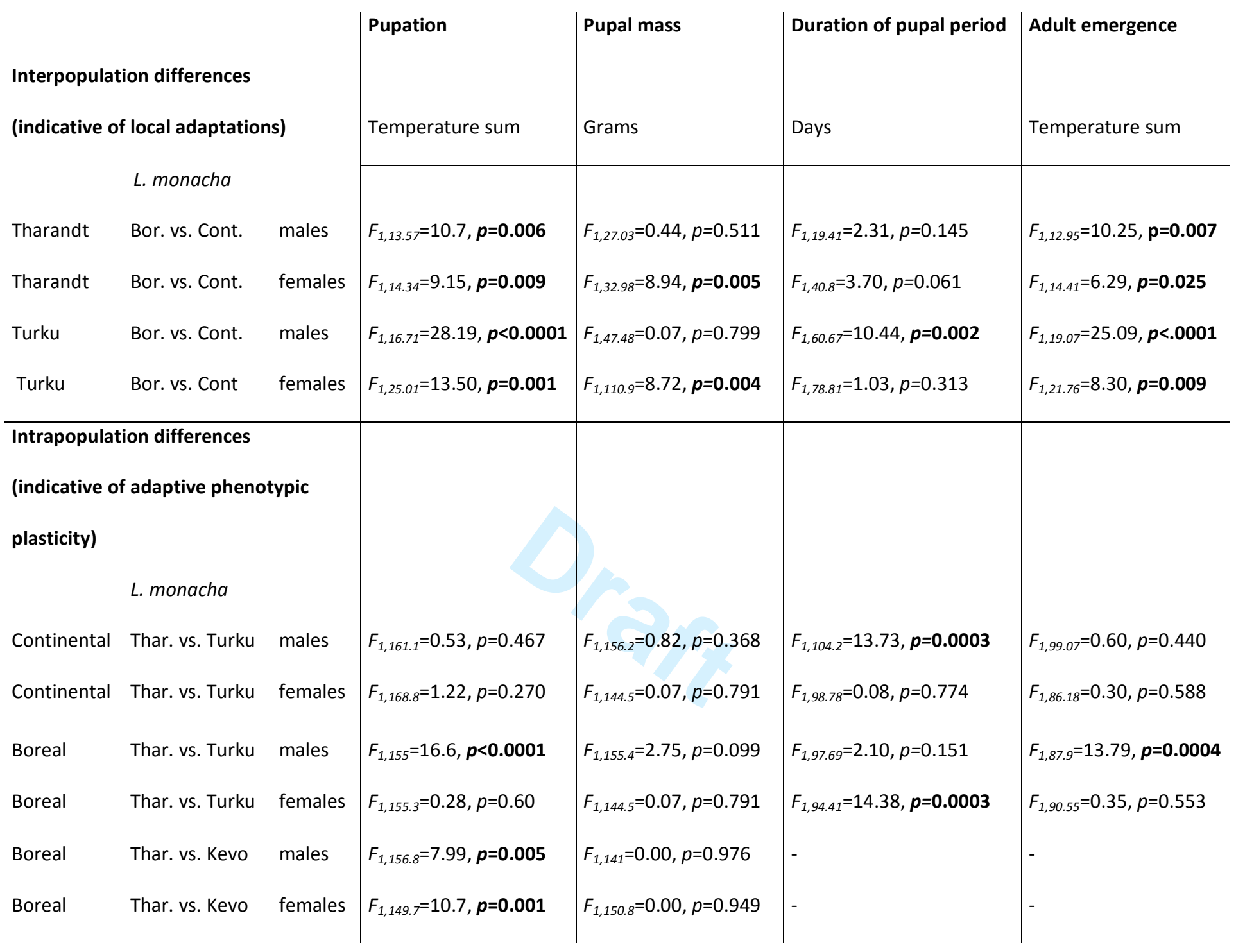




\begin{tabular}{|c|c|c|c|c|c|c|}
\hline Boreal & Turku vs. Kevo & males & $F_{1,150.5}=0.47, p=0.495$ & $F_{1,153.1}=2.00, p=0.159$ & - & - \\
\hline Boreal & $\begin{array}{l}\text { Turku vs. Kevo } \\
\text { L. dispar }\end{array}$ & females & $F_{1,154.4}=7.14, \boldsymbol{p}=\mathbf{0 . 0 0 8}$ & $F_{1,152.8}=1.20, p=0.274$ & - & - \\
\hline Continental & Thar. vs. Turku & males & $F_{1,204.2}=2.1, p=0.149$ & $F_{1,204}=1.20, p=0.274$ & $F_{1,107.6}=12.20, \boldsymbol{p}=\mathbf{0 . 0 0 0 7}$ & $F_{1,107.4}=1.00, p=0.320$ \\
\hline Continental & Thar. vs. Turku & females & $F_{1,203.6}=5.27, \boldsymbol{p}=\mathbf{0 . 0 2 3}$ & $F_{1,207.1}=2.36, p=0.126$ & $F_{1,113}=6.58, \boldsymbol{p}=\mathbf{0 . 0 1 2}$ & $F_{1,110.3}=0.39, p=0.534$ \\
\hline Continental & Thar. vs. Kevo & males & $F_{1,204}=145.3, \boldsymbol{p}<0.0001$ & $F_{1,198}=1.64, p=0.202$ & - & - \\
\hline Continental & Thar. vs. Kevo & females & $\begin{array}{l}F_{1,201.7}=129.69 \\
\boldsymbol{p}<0.0001\end{array}$ & $F_{1,208.6}=7.20, \boldsymbol{p}=\mathbf{0 . 0 0 8}$ & - & - \\
\hline Continental & Turku vs. Kevo & males & not compared & not compared & - & - \\
\hline Continental & Turku vs. Kevo & females & not compared & not compared & - & - \\
\hline \multicolumn{7}{|c|}{ Influence of host plant on L. dispar } \\
\hline L. dispar & birch vs. oak & & $\begin{array}{l}\text { Oak } 55 \text { dd5 lower } \\
S E=11.0 \\
F_{1,104.7}=24.9, \boldsymbol{p}<0.0001\end{array}$ & $\begin{array}{l}\text { Oak } 0.11 \mathrm{~g} \text { heavier } \\
S E=0.046 \\
F_{1,111.2}=5.87, \boldsymbol{p}=\mathbf{0 . 0 1 7}\end{array}$ & $\begin{array}{l}\text { (Oak } 0.8 \text { days shorter) } \\
S E=0.67 \\
F_{1,73.33}=1.28, p=0.262\end{array}$ & $\begin{array}{l}\text { Oak } 75 \text { dd5 lower } \\
S E=16.9 \\
F_{1,69.5}=19.93, p<.0001\end{array}$ \\
\hline
\end{tabular}

